\title{
Age-Related Changes in Serum Guanidinoacetic Acid in Women
}

\author{
A. OLAH ${ }^{1}$, V. STAJER ${ }^{2}$, L. RATGEBER ${ }^{1}$, J. BETLEHEM ${ }^{1}$, S. M. OSTOJIC ${ }^{1,2}$ \\ ${ }^{1}$ Faculty of Health Sciences, University of Pécs, Pécs, Hungary, ${ }^{2}$ Faculty of Sport and Physical \\ Education, University of Novi Sad, Novi Sad, Serbia
}

Received April 14, 2019

Accepted September 25, 2019

Epub Ahead of Print October 25, 2019

\begin{abstract}
Summary
Guanidinoacetic acid (GAA) is a fundamental intermediate in cellular bioenergetics, with circulating levels of GAA often reflects disturbances in its conversion due to many intrinsic and extrinsic factors, including gender or age. Here, we evaluated serum GAA in 172 healthy women aged 18 to 65 years, with age found to significantly predict serum GAA concentrations ( $r=0.29, P=0.03)$. This perhaps nominates serum GAA as a novel gender-specific proxy of impaired bioenergetics with aging.
\end{abstract}

\section{Key words}

Guanidinoacetic acid • Creatine • Aging • Body mass index • Gender

\section{Corresponding author}

S. M. Ostojic, FSPE Applied Bioenergetics Lab, University of Novi Sad, Lovcenska 16, Novi Sad 21000, Serbia. E-mail: sergej.ostojic@chess.edu.rs

Guanidinoacetic acid (GAA) is a natural amino acid derivative, and an intermediary compound of energy metabolism in humans (Ostojic 2016). Synthesized mainly in the kidney and pancreas from glycine and arginine, GAA is transferred to the liver to yield creatine, a key molecule in cellular bioenergetics (Brosnan and Brosnan 2007). Since GAA is minimally presented in food ( $<1.0 \mathrm{mg}$ per $\mathrm{kg}$ of meat) (European Food Safety Authority 2009) whereas the fraction excreted via urine and feces was negligible (Lemme et al. 2007), circulating levels of GAA appears to reflect the equilibrium between its synthesis and metabolic utilization. Various conditions affect serum GAA levels, including creatine deficiency syndromes (Mercimek-Mahmutoglu and Salomons 2009), chronic kidney disease and diabetes mellitus (Tsubakihara et al. 2012), or exhaustive exercise (Sotgia et al. 2007). Specifically, values seem to be genderdependent, with healthy girls have higher leakage of GAA as compared to male peers (Joncquel-Chevalier Curt et al. 2013). This perhaps happens due to the functional inhibition of SLC6A8, a main cellular transporter for GAA, by estrogen in pubertal age (Heneweer et al. 2007). However, little information is currently available concerning age-related dynamics of serum GAA in adult women. Since kidney function declines with age (Cedikova et al. 2016, Gekle 2017), GAA production might be reduced in normal aging, with lower serum GAA anticipated in healthy mature women. In addition, an impaired activity of two enzymes involved in creatine synthesis (L-arginine:glycine amidinotransferase (AGAT) and guanidinoacetate N-methyltransferase (GAMT)) in adult subjects (McClure et al. 2007), could also contribute to a cumulative impact of aging on serum GAA biokinetics in women. Therefore, the aim of this cross-sectional study was to describe the link between age and serum GAA levels in apparently healthy women aged 18 years or older.

The data from a subsample of healthy, community-dwelling women that voluntarily participated in the Diet and Physical Activity for Health Initiative (DiPAH) has been analyzed for this report. The DiPAH started in 2008 as a long-term, nationally recognized health study that was focused on strategies for the prevention of chronic diseases in the adult Serbian population. Additional details about DiPAH, including 
participants characteristics and study design, are available elsewhere (Ostojic et al. 2018). The study was conducted according to the guidelines laid down in the Declaration of Helsinki, and all procedures were approved by the local IRB at the University of Novi Sad. Eligibility criteria for this analysis included non-pregnant women aged between 18 and 65 years, free from acute and chronic medical conditions, and from taking dietary supplements, and not involved in a programmed exercise regimen at the study commence. Of 345 DiPAH subjects (188 women) initially screened, 172 women were eligible and consented to participate in the current study. Height was measured by a stadiometer (Seca, Hamburg, Germany), while body weight was measured with a digital scale (Omron BF 511, Kyoto, Japan), with body mass index (BMI) calculated as weight in kilograms divided by the square of height in meters. Levels of GAA and creatine in serum and 24-hour urinary aliquots were measured by liquid chromatography-tandem mass spectrometry (SCIEX LC-MS/MS 5500QTRAP, AB Sciex Ltd., Canada). A multiple linear regression model with a stepwise method (adjusted for body mass index, urinary GAA and serum creatine) was employed to examine the relationships between age and GAA levels. The significance level was set at $P \leq 0.05$. The data were analyzed using the statistical package SPSS, version 24.0 for Mac (IBM SPSS Statistics, Chicago, IL, USA).

The mean \pm SD (range) age and BMI for study

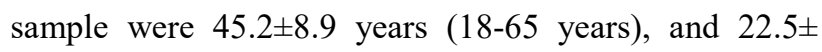

$2.8 \mathrm{~kg} / \mathrm{m}^{2}\left(17.1-33.2 \mathrm{~kg} / \mathrm{m}^{2}\right)$, respectively. Serum GAA and creatine levels were $2.6 \pm 0.8 \mu \mathrm{mol} / \mathrm{l}$ and $25.1 \pm$ $8.3 \mu \mathrm{mol} / 1$, respectively, urinary GAA was $155.9 \pm$ $50.6 \mu \mathrm{mol} / 1$. A significant positive correlation was found between age and serum GAA levels $(r=0.29, P=0.03)$ (Fig. 1). Hierarchical multiple regression revealed that the model as a whole (including age as a predictor variable, and body mass index, urinary GAA and serum creatine as control variables) explained $29.1 \%$ of the variance in serum GAA levels $(P<0.001)$, with control variables account for $19.8 \%$ of the variability in serum GAA $(P=0.001)$. The evaluation of the contribution of each independent variable revealed that age and serum creatine make unique statistically significant contributions to our model $(24.5 \%$ and $38.1 \%, P<0.05)$, while neither body mass index $(2.5 \%, P=0.77)$ or urinary GAA $(14.1 \%$, $P=0.21$ ) made significant unique contributions to our model. No correlation was found between age and serum creatine levels ( $r=0.08, P=0.48)$.

The present study reported a significant link between age and serum GAA in apparently healthy women aged 18 years and above. Higher circulating levels of GAA were accompanied by advanced age, with BMI and urinary GAA found to be irrelevant confounding variables. While circulating creatine levels remained essentially unrelated with the age of adult women in our cohort, age-related elevation of serum GAA might be recognized as a sensible biomarker of impaired creatine metabolism in this population.

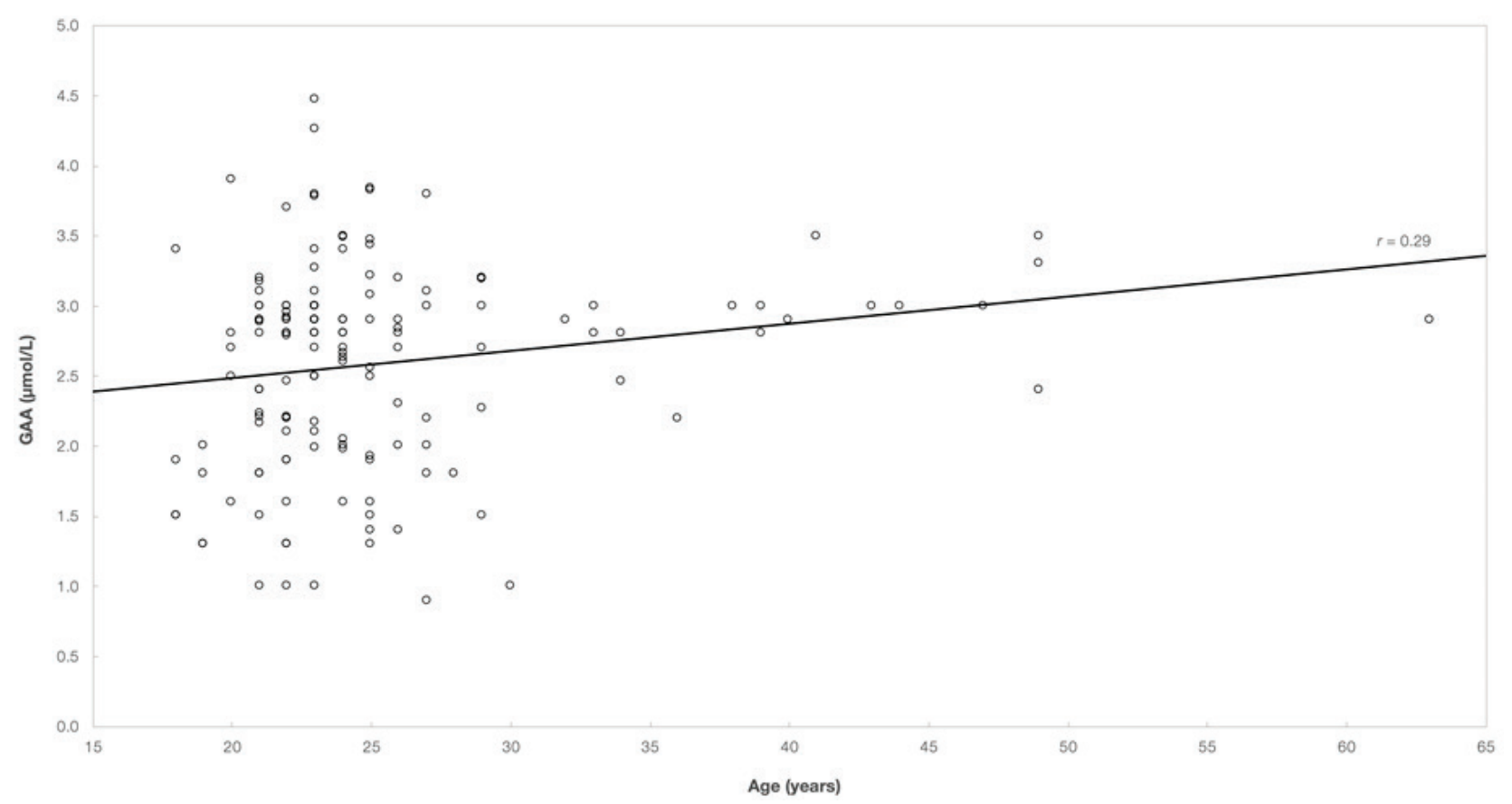

Fig. 1. Correlation between age and serum guanidinoacetic acid (GAA) levels in healthy adult women $(n=172)$. 
Abnormal serum GAA level is considered a clinical marker of altered bioenergetics in different inherited or acquired disorders, from inborn errors of creatine metabolism to cardiometabolic diseases to specific physiological conditions. Having high serum GAA could be a consequence of either augmented synthesis or GAA loading (Ostojic et al. 2013), GAA accumulation caused by deficiency of enzyme catalyzing the methylation of GAA to creatine and transport blockage (Mercimek-Mahmutoglu and Salomons 2009), or limited excretion due to sex hormones-related impact on GAA recovery in the kidney (Joncquel-Chevalier Curt et al. 2013). Specifically, a significant gender differences were observed in GAA biodynamics between healthy men and women, with values in GAA excretion significantly higher in female than in male subjects $(90.0$ vs. $77.6 \mathrm{mmol} / \mathrm{mol}$ creatinine), while serum GAA appears to be similar in both subsamples $(1.5 \pm 0.6 \mu \mathrm{mol} / 1$ in men vs. $1.4 \pm 0.6 \mu \mathrm{mol} / 1$ in women) (Joncquel-Chevalier Curt et al. 2013). This population study evaluated 6334 participants (1923 women) yet provided no genderspecific serum GAA levels across different age groups. Nevertheless, the results for a mixed group displayed an age-related increase in serum GAA levels, with circulating GAA rise from $1.3 \pm 0.5 \mu \mathrm{mol} / 1$ (subject group $>10$ years $)$ to $1.7 \pm 0.5 \mu \mathrm{mol} / 1(10-15$ years $)$ to $2.3 \pm$ $0.8 \mu \mathrm{mol} / 1$ (subject group $>15$ years). GAA in plasma was confirmed to be age-dependent in another study (Almeida et al., 2004), with higher values for GAA reported in subjects older than 15 years as compared to younger counterparts (1.0-3.5 $\mu \mathrm{M}$ vs. 0.4-1.8 $\mu \mathrm{M})$. However, neither study provided data for adult population, women in particular. Although our study provided overall confirmatory data, the mean serum GAA found in our study with adult women $(2.6 \pm 0.8 \mu \mathrm{mol} / \mathrm{l})$ appears to be somewhat higher as compared to previous studies where subjects were typically 15 years or younger. This perhaps illustrates an age-related trend for GAA rise in women, corroborated by a positive correlation between age and serum GAA found in our report. An age-dependent increase in serum GAA in adult women could be due to hormonal alterations across different age. Theoretically, less estrogen available in women with advanced age could diminish its inhibitory effect on GAA recovery kinetics in the kidney (JoncquelChevalier Curt et al. 2013), making more GAA reabsorbed from the urine and thus available for the circulation. However, this theory appears to be improbable since urinary excretion of GAA was found to be an irrelevant contributing factor. Another hypothesis accounts for a possible age-dependent alteration of bioenergetics enzyme machinery (Kaczor et al. 2006, McClure et al. 2007) that could alter creatine synthesis and consequently enable GAA accumulation in the blood. This requires additional in vitro studies evaluating possible enzyme dysregulation in age- and genderdependent assays. GAMT expression appears to be under the control of sex hormones (Lee et al. 1994), with the enzyme activity might be different in mature women. Furthermore, there are some indications that AGAT and GAMT expressions may be modulated by dietary factors (for review see Wyss and Kaddurah-Daouk, 2000), which should be also accounted for future studies. In addition, monitoring other biomarkers of GAA metabolism in women, including plasma arginine and glycine kinetics, and fractional elimination rates for GAA, along with age-related changes in hormonal status, are highly warranted to address GAA-creatine axis behavior in human physiology and pathophysiology.

In conclusion, circulating GAA increases with age in adult healthy women, implying altered homeostasis between GAA synthesis, utilization and/or elimination in this population. A strong correlation found between serum GAA and age might advance its use as a novel genderspecific proxy of impaired bioenergetics with aging. Further research should involve mechanistic approach in evaluating GAA biodynamics in human studies.

\section{Conflict of Interest}

There is no conflict of interest.

\section{Acknowledgements}

This work was partly supported by the Serbian Ministry of Education, Science and Technological Development (175037), the Provincial Secretariat for Higher Education and Scientific Research (114-451-710), the Faculty of Sport and Physical Education, Novi Sad, and the Center for Health, Exercise and Sport Sciences, Belgrade.

\section{References}

ALMEIDA LS, VERHOEVEN NM, ROOS B, VALONGO C, CARDOSO ML, VILARINHO L, SALOMONS GS, JAKOBS C: Creatine and guanidinoacetate: diagnostic markers for inborn errors in creatine biosynthesis and transport. Mol Genet Metab 82: 214-219, 2004. 
BROSNAN JT, BROSNAN ME: Creatine: endogenous metabolite, dietary, and therapeutic supplement. Annu Rev Nutr 27: 241-261, 2007.

CEDIKOVA M, PITULE P, KRIPNEROVA M, MARKOVA M, KUNCOVA J: Multiple roles of mitochondria in aging processes. Physiol Res 65 (Suppl 5): S519-531, 2016.

EUROPEAN FOOD SAFETY AUTHORITY: Safety and efficacy of guanidinoacetic acid as feed additive for chickens for fattening. EFSA J 988: 1-30, 2009.

GEKLE M: Kidney and aging - A narrative review. Exp Gerontol 87: 153-155, 2017.

HENEWEER M, HOUTMAN R, POORTMAN J, GROOT M, MALIEPAARD C, PEIJNENBURG A: Estrogenic effects in the immature rat uterus after dietary exposure to ethinylestradiol and zearalenone using a systems biology approach. Toxicol Sci 99: 303-314, 2007.

JONCQUEL-CHEVALIER CURT M, CHEILLAN D, BRIAND G, SALOMONS GS, MENTION-MULLIEZ K, DOBBELAERE D, CUISSET JM, LION-FRANÇOIS L, DES PORTES V, CHABLI A, VALAYANNOPOULOS V, BENOIST JF, PINARD JM, SIMARD G, DOUAY O, DEIVA K, TARDIEU M, AFENJAR A, HÉRON D, RIVIER F, CHABROL B, PRIEUR F, CARTAULT F, PITELET G, GOLDENBERG A, BEKRI S, GERARD M, DELORME R, PORCHET N, VIANEY-SABAN C, VAMECQ $\mathrm{J}$ : Creatine and guanidinoacetate reference values in a French population. Mol Genet Metab 110: 263-267, 2013.

KACZOR JJ, ZIOLKOWSKI W, ANTOSIEWICZ J, HAC S, TARNOPOLSKY MA, POPINIGIS J: The effect of aging on anaerobic and aerobic enzyme activities in human skeletal muscle. J Gerontol Biol Sci Med Sci 61: 339-344, 2006.

LEE H, OGAWA H, FUJIOKA M, AND GERTON GL: Guanidinoacetate methyltransferase in the mouse: extensive expression in Sertoli cells of testis and in microvilli of caput epididymis. Biol Reprod 50: 152-162, 1994.

LEMME A, TOSSENBERGER J, RINGEL J: Digestibility and availability of the creatine source guanidinoacetic acid in broilers. Poult Sci 86: 153, 2007.

MCCLURE WC, RABON R, OGAWA H, TSENG BS: Upregulation of the creatine synthetic pathway in skeletal muscles of mature mdx mice. Neuromuscul Disord 17: 639-650, 2007.

MERCIMEK-MAHMUTOGLU S, SALOMONS GS: Creatine Deficiency Syndromes. In: Adam MP, Ardinger HH, Pagon RA, Wallace SE, Bean LJH, Mefford HC, Stephens K, Amemiya A, Ledbetter N, (Eds.) GeneReviews ${ }^{\circledR}$ [Internet]. Seattle (WA): University of Washington, Seattle, 1993-2017. 2009 Jan 15 [updated 2015 Dec 10].

OSTOJIC SM, NIESS B, STOJANOVIC M, OBRENOVIC M: Creatine metabolism and safety profiles after six-week oral guanidinoacetic acid administration in healthy humans. Int J Med Sci 10: 141-147, 2013.

OSTOJIC SM, VALDEMAR S, LONCAR D, VRANES M, ZRNIC N, SEKULIC D: Guanidinoacetic acid and creatine are associated with cardiometabolic risk factors in healthy men and women: a cross-sectional study. Nutriens 10: $87,2018$.

OSTOJIC SM: Guanidinoacetic acid as a performance-enhancing agent. Amino Acids, 48: 1867-1875, 2016.

SOTGIA S, CARRU C, CARIA MA, TADOLINI B, DEIANA L, ZINELLU A: Acute variations in homocysteine levels are related to creatine changes induced by physical activity. Clin Nutr 26: 444-449, 2007.

TSUBAKIHARA Y, HAYASHI T, SHOJI T. Guanidinoacetic acid (GAA) in patients with chronic kidney disease (CKD) and diabetes mellitus (DM). Kid Res Clin Pract 31: A81, 2012.

WYSS M, KADDURAH-DAOUK R: Creatine and creatinine metabolism. Physiol Rev 80: 1107-1213, 2000. 